\title{
Protected Banking Verification By Figure Pixel Comparison And Bitcoin Transaction Using Blockchain
}

\author{
M.P.Karthikeyan ${ }^{1}$, C. Balakrishnan ${ }^{2}$, Karthik Elangovan ${ }^{3}$, T. C. Jermin Jeaunita ${ }^{4}$ \\ ${ }^{1}$ Assistant Professor, Department of Computer Science and Engineering at RMK Engineeing College \\ ${ }^{2}$ Associate Professor, S.A.Engineering College, Chennai, \\ ${ }^{3}$ Assistant Professor, Saveetha school of Engineering, Saveetha Institute of Medical and Technical Sciences \\ Chennai, \\ ${ }^{4}$ Assistant Professor, Department of Computer Science and Engineering from St. Xavier's Catholic College of \\ Engineering, Tamilnadu
}

Article History:Received:11 november 2020; Accepted: 27 December 2020; Published online: 05 April 2021 \begin{abstract}
E-banking is a safe, fast, easy and efficient electronic service that enables you access to bank account and to carry out online banking services, 24 hours a day, and 7 days a week. Through web, clients can get to their record from anyplace on the planet. Acknowledgment of substantial customer is a significant issue in E-banking. The security issue emerges because of unavoidable hacking of banking web. Duplicate sites are a sort of online information deception that hopes to take secret information, similar to e-money passwords and money exchange information from clients. Hence a structure having figure pixel appraisal for purchaser approval principally based barring chain strategy. In the proposed framework, for each money given up by the customer, we produce an ID for every cash, when any aggregate of sum is moved, the ID of the monetary forms may be moved, so we can follow the method for the money going around.Thus, the graphical secret key has been proposed with the guide of numerous scientists as a chance to content based secret key. Usage of hyperlink chain graphical secret key which utilizes round resilience makes the framework more made sure about than current.
\end{abstract}

Keywords: E-coin, Graphical passwords, Block chain, Pixel comparison

\section{INTRODUCTION}

The use of PC frameworks and web has become so unavoidable so it impacts the entirety of the financial areas. Wellbeing has come to be the greatest imperative angle in these day's financial exchange contraption since banks are committed to offer secure focus banking contributions to their customers. To accomplish this reason realness of the clients is required; for example, handiest the approved clients can partake inside the exchange. With respect to the cause, banks utilizes Biometrics based verification frameworks but unavoidable malignant games database of the financial gadget isn't comfortable. Cunning programmers can get biometric measurements of clients from the financial gathering's database and later can utilize it for fake exchanges. To keep away from this disastrous subjects', picture handling approach is utilized. Picture preparation is an incredible encryption plot wherein data spread in the photos and unscrambled just by means of human seen framework. Now recommend a quiet XORactivity based photograph handling method to deal with secure financial exchange. Directly here we review the instance of shared service activity. Normally, in the banking segment, Biometrics based confirmation is utilized. Biometrics based confirmation framework works with the guide of method for getting crude biometric insights (e.g., Face picture, Fingerprints and so on.) from the subject, removing highlight set from the crude information and looking at the list of capabilities against the outline that is put away in the database so as to validate the subject or to check guaranteed character. Security of any foundation/association relies upon basic plan innovation center products and the vast majority of the structure of the database. Each exchange worldly has sway on the database. In this way, programmers consistently attempt to hack the database. The financial framework while offering web empower center administration's significant issue is confirmation of the client. Numerous procedures are utilized for this reason. For example, Secret key based verification, Smart card based confirmation, Biometric based validation framework. Every one of these systems is required to keep up a database, thus powerless for hacking. Database contains private data subsequently there is probability of protection loss. One Simplest type of Image processing or visual mystery sharing plan thinks about twofold picture as info and manages every single pixel autonomously. To encode a pixel of the mystery picture, we split the mystery pixel into $\mathrm{n}$ forms so that if all $\mathrm{n}$ adaptations are imprinted on transparencies and superimposed the first mystery pixel is uncovered. This procedure must be applied for the whole mystery picture.

Subsequently n portions of unique mystery picture are prepared, to uncover the mystery print the offers on transparencies and superimpose them. Proposed confirmation strategy utilizes XOR activity based picture preparing strategies to guarantee verification just as security of the data put away in the bank database.

${ }^{*}$ Corresponding author: M.P.Karthikeyan

${ }^{1}$ Assistant Professor, Department of Computer Science and Engineering at RMK Engineeing College 


\section{EXISTING SYSTEM}

In existing structure, same customers have the different online records they are using tantamount passwords for that records. In that time the software engineers where a foe may attack a record of a customer using the equivalent or practically identical passwords of his/her distinctive less fragile records. It is secure against mystery word related ambushes, also as can restrict replay attacks, bear surfing attacks, phishing attacks, and data break scenes. The existing system is essentially money trade will be kept up in such a manner like the total to be traded and check of the rupees will be kept up. The above procedure is simply used to keep up the measure of total is traded from each and every record this thought will be admirable if there ought to emerge an event of customer see yet not to reduce the dull money in the point of view of the government. Different from existing works, we abuse dynamic check accreditations nearby customer driven access control to handle the static capability issue. In customary methodology if you have to open one record infers we will give the username and give the watchword. So if it's possible another person may track our record details.

\section{PROPOSED SYSTEM}

In the proposed system, for every single exchange handled in our application given up by the client, we will make the intriguing id for each money. When the total is exchanged from source to objective, not just the sum and check of the cash will be taken in spite of that intriguing id will besides be exchanged with the target that we can follow the strategy for the money going around. If the extraordinary id isn't disturbed then we can isolate which is the last record that has entered and from that record it is unpretentious accordingly we can keep up examining. In this framework, we have shown username, puzzle word and give the unequivocally picked picture pixels. On the off chance that we are not picked adjust inspiration driving the photograph pixels surmises the photograph is changed strongly. Using this cryptographic frameworks the course for client driven access control that limits the dangers of different ambushes. Its configuration gives insurance against different puzzle word related strikes, for example, bear surfing ambushes and direct perception assaults. The customer is legitimately shielded from utilizing static usernames and passwords that can be seen by utilizing warm imaging, or by perceiving the squeezed keys utilizing a mechanical vibration assessment.

\section{SYSTEM ARCHITECTURE}

Here we have provided a clear architecture for our proposed system.

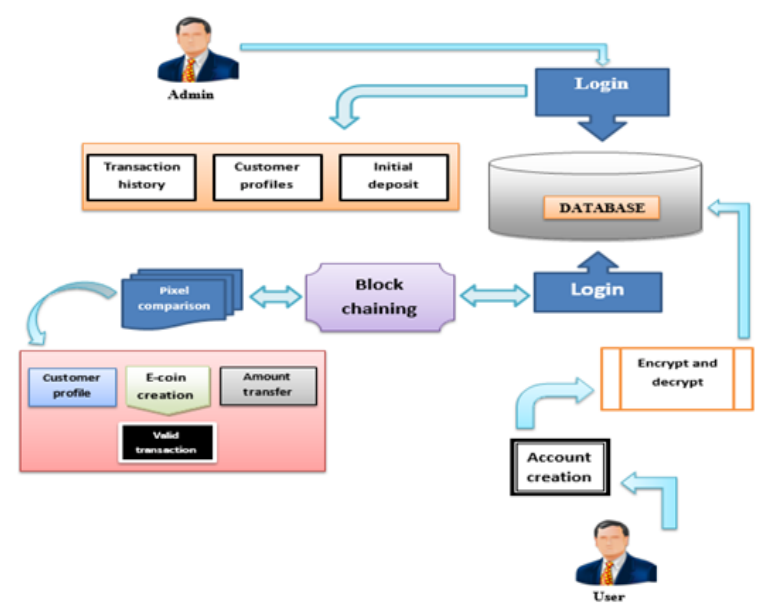

Fig. 1.1

Here the system works on two phase one is admin part and the user part. Admin can check the transaction, customer details and cash details. In the user part the creation of an individual bankaccount user data will be encrypted for security and before logging in the blocking chain is implemented for pixel comparisons. If the selected pixel matched then used is allowed to login. Users can do transaction and while making money transfer an E-coin is generated randomly according to the note and amount is deposited to the account in the form of that e-coin key.

\section{A. ADMINISTRATOR}

Administrator does the work of initializing the amount transfer in the form of e-coins. As per the request of the customer the modes of e-coins are deposited into the accounts of the customer.

B. CUSTOMER ACCOUNT

Customer is the payer who sends the amounts to the payee. First, the customer needs to register the login details including the credentials. Second, the customer needs to pick image pixels as their secondary 
password.Then the login is done using the username, password and by choosing the pixels of the images.

C. PIXEL COMPARISON

The security in login is achieved through pixel comparison. The customer chooses images of their own and selects pixels in those respective images. The pixel points get stored in the database. In addition to username and password, the correct pixel must be chosen by the customer to get logged in to the account.

\section{E-COIN CREATION}

E-coin creation is done from the administration side. The administrator deposits the modes of e-coins to be transferred by the payee to the payer.

\section{USER AUTHENTICATION MODULE}

Each and every customer login the page by then makes the trade and uses this application. Validness is affirmation that a message, trade, or other exchange of information is from the source it cases to be from.

Validness incorporates confirmation of character. We can check validity through affirmation. Select and login decision in greeting page. Each and everycustomer needs to enroll as the new customer for login.

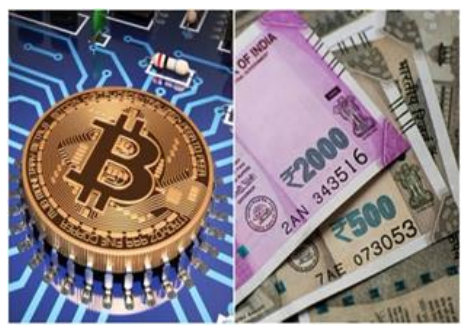

Customers need to fill all the essentials for security reasons, so they should fill every single unobtrusive component for special focal points. All of the unpretentious components saved in different manners. Make a new table for each customer and extra focal points in a way table. Those characteristics used institutionalize and check for money transmission getting ready. Here to affirm the customer focal points for one time mystery key sent to your enrolled mail id. By then enter the best approach to affirm your unobtrusive components and can find a good pace. Customers open to see the altar, see trade history and make trade of its own and customer in like manner see what number of money they have.

\section{VARIOUS CURRENCIES}

That monetary form idea is one of the security layers for lessening the dark cash spread. There are three different monetary forms model,

\section{2,000 Currencies}

2. 500 Currencies

3. 100 Currencies

That way separates cash in the E-Coin Application. The diverse money show used uncommon impetus for each rupee note and easy to perceive the rupees. That exceptional regard used to keep up a key good ways from fake money in the money transmission and moreover easy to find each rupee note is the spot it now. That exceptional regard made normally so every money transmission is incredibly secure. That remarkable regard is the basic key so extraordinary regard can't create the same regard. Each and every customer has some portion of money and each and every money or cash has an exceptional id.

\section{ALLOCATE INITIAL CURRENCIES TO THE INDIVIDUAL}

This apportions starting money related measures to the individual model simply get to agree to Admin. The Admin finds a workable pace after the login with executive approval inconspicuouscomponents, for the most part can't find a good pace coin application. That executive is put the hidden money as a motivating force for each customer. The Customer store money in account suggests at the time admin produce the uncommon motivating force for each cash note. That exceptional regard stockroom on rupee note number and the measure of rupee note for example 2,000 or 500 or hundred.

\section{Fig. 1.2}

After that store money in the customer account. Directors have a chance to check each and every customer's trade focal points and moreover check the id of that money related guidelines.

\section{TRANSFER OF DIGITAL CURRENCIES ACROSS INDIVIDUALS}

Each and every trade is made by the customer in a manner of speaking. Customers need to enter the correct untouchable record number and right name of payee. After that, customers need to pick how a lot of aggregate will trade to the others and they pick what number of money related guidelines have sent from different sorts of fiscal benchmarks like from Thousand Currencies, Five Hundred Currencies, and Hundred Currencies. By 
then incorporate the trade date and time. Aggregate will be traded from one customer to another. The Currencies id will exchange or moved from one customer table to payee account table. So, we can without quite a bit of a stretch perceive the money, which customer has those financial structures. So we have perceived the dull money and we can without quite a bit of a stretch lessen the dim money masses. Progressed financial structures will reliably be a more affordable monetary system to keep up and use than a fiat money, to a limited extent when we consider the expense of scaling and security as time goes on, and on an overall scale. On account of the intriguing improvement of electronic financial guidelines from a security perspective, progressed fiscal norms make perfectly secure money structures still. Out of the box, through cryptographic functionalities fused explicitly with cutting edge money shows; they are degrees progressively secure, capable, and versatile than fiat money. Fiat money must be watched from counter-fitting, keeping cash distortion, note pulverization, and physical burglary. Fiat money will constantly be all the more exorbitant to organization, use, and keep up when all is said in a done cash related system than any kind of mechanized cash structure considering those deficiencies and blemishes. Electronic financial structures have more vital security and flexibility than their fiat accomplices too.

VIII.

\section{TRACKING OF CURRENCIES}

The money in the application has an uncommon ID which is created by our application. To keep an eye out for the money related structures traded, it is critical to follow the money which is traded. To follow we use the stand-out ID which is created to take care of the in DB, some banks do track several the sequential numbers from the cash bundles that they send for repayment/trade to various banks or money chest. This record is helpful for the Police to keep a watch on these numbers to follow the blameworthy gatherings in case of burglary in the midst of improvement of the cash. At the point when a customer trades the total to another customer the ID's are moved to the beneficiaries table with this we can follow the money with whom it starts at now available.

\section{SECURED LOGIN}

A viable and helpful customer affirmation plot using singular contraptions that utilizes particular cryptographic locals, for instance, encryption, propelled mark, pixel assurance. The procedure benefits by the expansive usage of figuring and diverse savvy advantageous devices that can enable customers to execute a protected check show. It keeps up the static username and mystery key tables for recognizing and affirming the validity of the customers who login. Besides, the image pixel is used to open the record. If we do not pick change point picture suggests the record won't open. It is a secure method.

X.

\section{CONCLUSION}

This is the endeavor which can change the financial status of our nation in the event that it is executed by the hold bank and the huge research is going considering the bitcoin so our idea will be significant for the geniuses. As an issue of first importance, we should need to assess utilizing lightweight cryptographic systems in our outline. Second, we intend to break down the outline of various client driven access control models. Our proposed arrangement is unquestionably not difficult to-learn and simple to-use since clients do nothing past entering one time username and confirmation code. By then selecting the pixel of picture, on the off chance that it is right entering represent the most part pixels change dependably. The username, watchword is memory vigilant straightforward in light of the fact that clients of our course of action don't need to audit any mystery whatsoever. In context of the structure, our answer is adaptable for clients since it decreases the risk of username/secret word reuse transversely completed different districts and associations. Note that we are using an individual contraption that is passed on by the client when in doubt and the client doesn't have to pass on extra equipment or any physical request for endorsement. This idea will be to an incredible degree productive any place all through the world considering its uncommon id age for every single note submitted to the framework.

\section{REFERENCES}

J. Ma, W. Yang, M. Luo, and N. Li, “A study of probabilistic password models," in

Proceedings of 2014 IEEE Symposium on Security and Privacy, May 2014, pp. 689-704.

Y. Li, H. Wang, and K. Sun, "Personal information in passwords and its security 2017.

implications," IEEE Transactions on Information Forensics and Security, vol. 12, no. 10, pp. 2320-2333,Oct.

H. M. Sun, Y. H. Chen, and Y. H. Lin, "oPass: A user authentication protocol resistant to password stealing and password reuse attacks," IEEE Transactions on Information Forensics and Security, vol. 7, no. 2, pp. 651663, Apr. 2012. 
A. Biryukov, D. Dinu, and D. Khovratovich, "Argon2: New generation of memory-hard functions for password hashing and other applications," in Proceedings of 2016 IEEE European Symposium on Security and Privacy, Mar. 2016, pp. 292-302.

D. Zhao, W. Luo, R. Liu, and L. Yue, "Negative iris recognition," IEEE Transactions on Dependable and Secure Computing, vol. 15, no. 1, pp. 112-125, Jan. 2018.

R. Liu, W. Luo, and X. Wang, "A hybrid of the prefix algorithm and the q-hidden algorithm for generating single negative databases," in Proceedings of 2011 IEEE Symposium on Computational Intelligence in Cyber Security, Apr. 2011, pp. 31-38.

J. Bonneau. The science of guessing: analyzing an anonymized corpus of 70 million passwords. In Proceedings of IEEE Symposium on Security and Privacy, pages 538-552. IEEE, 2012

D. Balzarotti, M. Cova, and G. Vigna. Clearshot: Eavesdropping on keyboard input from video. In IEEE Security \& Privacy, 2008.

J. Bonneau, C. Herley, P. C. Van Oorschot, and F. Stajano. The quest to replace passwords: A framework for comparative evaluation of web authentication schemes. In IEEE Security \& Privacy, 2012.

A. E. Howe, I. Ray, M. Roberts, M. Urbanska, and Z. Byrne.The psychology of security for the home computer user.In IEEE Security \& Privacy, 2012.

\section{XIII.AUTHORS PROFILE}

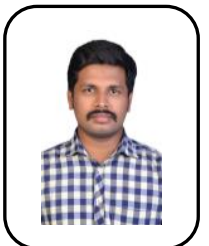

M. P. KARTHIKEYAN is currently an Assistant Professor in the Department of Computer Science and Engineering at RMK Engineeing College. He completed his B. E in Computer Science and Engineering from S. A. Engineering College, Tamilnadu, India in the year 2011 and M.Tech in Computer Science and Engineering from SRM University, Kattankulathur, Tamilnadu India in the year 2013. His research interests are Medical Image Processing, Peer to Peer networks, Network Security, and Artificial Intelligence.

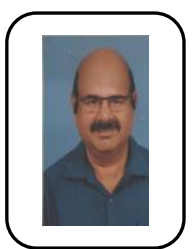

Mr.C.Balakrishnanreceived his M.E Degree from Anna University, Chennai, Tamil Nadu, India. $\mathrm{He}$ is currently an Associate Professor at S.A.Engineering College, Chennai, India. He is pursuing his $\mathrm{Ph} . \mathrm{D}$ degree in Information and Communication Engineering from MIT,Anna University. His current research interest includes Security in Wireless Networks.

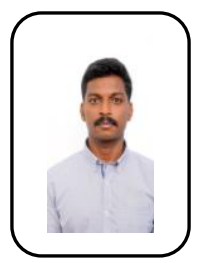

Mr.KarthikElangovanreceived his M.E. Degree from the Department of Computer Science and Engineering \& specialization in Knowledge Engineering at College of Engineering Guindy, Anna University, Chennai, Tamil Nadu, India. He is currently an Assistant Professor at Saveetha school of Engineering, Saveetha Institute of Medical and Technical Sciences Chennai, India. His current research interest includes Big Data analytic, Data Mining, and Machine Learning.

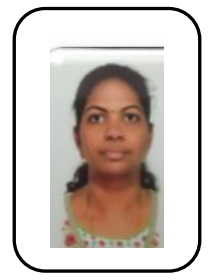

T. C. JerminJeaunitais currently an Assistant Professor in the Department of Computer Science and Engineering Computer Science and Engineering from St. Xavier's Catholic College of Engineering, Tamilnadu, India in the year 2003 and M.E in Computer Science and Engineering from Noorul Islam College of Engineering, Tamilnadu India in the year 2005. Her research interestsare Peer to Peer networks, Wireless Sensor Networks, IoT and Machine Learning. 